\title{
THE ASSESSMENT OF MITRAL STENOSIS BY PHONOCARDIOGRAPHY
}

\author{
BY \\ BERTRAND WELLS \\ From the Cardiological Department, St. Bartholomew's Hospital \\ Received February 11, 1954
}

Clinical assessment of the severity of mitral stenosis sometimes presents difficulties. The symptoms may be obscured by superadded effort syndrome or by limitation of activity imposed by the patient's doctor. The physical signs may reveal the presence of pulmonary hypertension or heart failure, but in their absence there may be little indication as to the size of the mitral orifice. The intensity of the diastolic murmur is of little value since the stenosis may be severe when the murmur is slight or even absent. The degree of pulmonary hypertension measured at cardiac catheterization and the degree of right ventricular hypertrophy on the electrocardiogram are not necessarily indications of the severity of mitral stenosis. When all the evidence is considered the assessment is reasonably accurate, but there is obvious room for more direct evidence as to the degree of stenosis. The crucial information required is the pressure gradient across the mitral orifice or the rapidity of filling of the left ventricle. Such information is not necessarily an indication of the size of the mitral orifice for the ability of the left ventricle to fill in diastole must be determined in part by the involvement of the chordæ tendineæ, by the location and mobility of the mitral orifice, and by myocardial factors. The present study provides evidence that the pressure gradient across the mitral valve and the rapidity of filling of the left ventricle can be estimated by a phonocardiographic technique.

\section{BASIS OF THIS STUDY}

The phonocardiogram of mitral stenosis usually shows two abnormal features. First there is an increase in the time interval between the onset of the QRS complex of the electrocardiogram and the onset of the maximal vibrations of the first heart sound. This interval will be called the " Q-1" interval (Fig. 1). Secondly there is a series of vibrations constituting the opening snap which follows the second heart sound. The interval between the beginning of the second heart sound and the beginning of the opening snap will be called the " $2-0 . S$." interval (Fig. 1). Occasionally the opening snap is absent in mitral stenosis and this is apparently an indication that the mitral valve is rigid and probably calcified: when calcification occurs in a valve that is still mobile and supple the opening snap does not disappear. The abnormal first sound and opening snap are often recorded on a logarithmic phonocardiogram when there is no auscultatory evidence of their presence (Wells, 1952). This alone indicates that the phonocardiogram is useful in the investigation of mitral stenosis.

Messer et al. (1951) demonstrated that in mitral stenosis with auricular fibrillation the Q-1 interval and the 2-O.S. interval are not constant but vary with the length of the preceding cardiac cycle. After a short $R-R$ interval (measured from the apex of the $R$ waves of the electrocardiogram) the Q-1 interval is long and the 2-O.S. interval is short. As the $R-R$ interval becomes longer the Q-1 interval becomes shorter and 2-O.S. interval becomes longer. As the authors point out, the only factor that can determine the variations in these measurements is the pressure gradient across the mitral orifice. When the pressure gradient is high after a short diastolic interval 


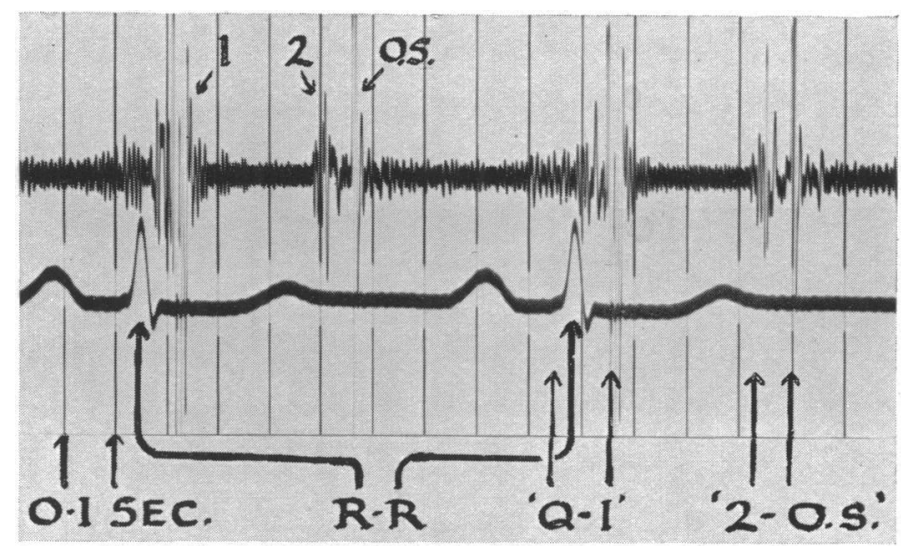

FIG. 1.-Synchronous phonocardiogram and electrocardiogram showing measurements of $\mathrm{Q}-1$ and 2-O.S. intervals and the preceding cycle length ( $R-R$ interval).

the left ventricle will take longer to reach the atrial pressure and the first heart sound will be delayed. As the atrial pressure remains high throughout systole the opening snap will occur early. This explanation seems reasonable, but other factors may have a bearing on the question. The greater filling of the left ventricle after a long diastolic interval may produce a more efficient and more forceful contraction which empties the ventricle more completely. This would accelerate the onset of the first heart sound and delay the opening snap. Fortunately it is not of great importance to differentiate between pressure and volume changes for both depend on the severity of the mitral stenosis.

If the work of Messer et al. is confirmed it is reasonable to carry the argument further. If the $\mathrm{R}-\mathrm{R}$ interval is plotted against the $\mathrm{Q}-1$ and 2-O.S. intervals the graph should indicate the severity of the mitral stenosis (Fig. 2). It may even be possible to arrive at the answer by a single reading of the three intervals which could be corrected by nomogram in the same manner as the Q-T interval is corrected. There are, of course, certain errors that might interfere with the accuracy of such a test. The onset of the QRS complex in the electrocardiogram may be delayed by the presence of an initial isoelectric interval in a single lead. The presence of auricular contraction may alter the pressure gradient in sinus rhythm and thereby invalidate the Q-1 interval. The absence of an opening snap in patients with rigid mitral valves will make a 2-O.S. interval unavailable.

\section{METHOD AND RESULTS}

Thirty patients were studied by phonocardiography before and after mitral valvotomy. Logarithmic tracings were taken on a Sanborn stethocardiette using the technique of Wells et al. (1949). The routine locations were (1) $1 \mathrm{~cm}$. internal to the apex beat, (2) the second interspace at the left sternal border, and (3) the fourth interspace at the left sternal border. In the last area the opening snap is usually best recorded, and when there is sinus rhythm the first heart sound is less obscured by a presystolic murmur. Lead II of the electrocardiogram was recorded synchronously as reference tracing. Tracings were taken a few weeks before operation and between the ninth day and the third month after operation. The tracings were taken in arrested respiration at the end of a quiet expiration, and were examined to verify that there were no significant changes due to the arrest of respiration or to the choice of location of the microphone.

\section{RESUlts}

Twenty-seven of the thirty patients had an opening snap on the phonocardiogram. At operation there was occasionally some calcification of the margins of the cusps but the cusps themselves were 
supple. The remaining three had no opening snap and the valve cusps were found to be both rigid and calcified; these three were eliminated from the study for the sake of simplicity.

Nine patients had auricular fibrillation and these were first examined to determine the relationship between the Q-1 interval and the $R-R$ interval of the preceding cardiac cycle. Graphs were drawn for each patient and showed an approximately linear relationship between the Q-1 interval and $\mathrm{R}-\mathrm{R}$ interval, provided the latter was between 0.6 and $1.2 \mathrm{sec}$. Over this range the $\mathrm{Q}-1$ interval decreased by $0.03 \mathrm{sec}$. (Fig. 2). Graphs were drawn in the same way for the 2-O.S. interval and the $\mathrm{R}-\mathrm{R}$ interval. Here the relationship was again approximately linear and the $2-O$.S. increased by 0.03 seconds over the $R-R$ range of 0.6 to 1.2 seconds. These findings confirmed the work of Messer et al. and showed that the Q-1 and 2-O.S. intervals might reasonably indicate the pressure gradient across the mitral valve.

The cases with sinus rhythm and those with auricular fibrillation were now considered together in order to see whether the Q-1 and 2-O.S. intervals would determine the severity of mitral stenosis. In the patients with sinus rhythm the range of cycle length was limited, but when a graph was drawn for each case it was almost always possible to read off without extrapolation the Q-1 and 2-O.S. intervals for a cycle length of $0.8 \mathrm{sec}$. (Fig. 2). These corrected Q-1 and corrected 2-O.S. intervals were now compared with the size of the mitral orifice as measured at operation. The length and breadth in centimetres of the mitral orifice were multiplied to give a single figure which could be used in a quantitative manner. Nineteen of the mitral orifices were $1 \times 1 \mathrm{~cm}$. or smaller, and the remaining eight were larger.
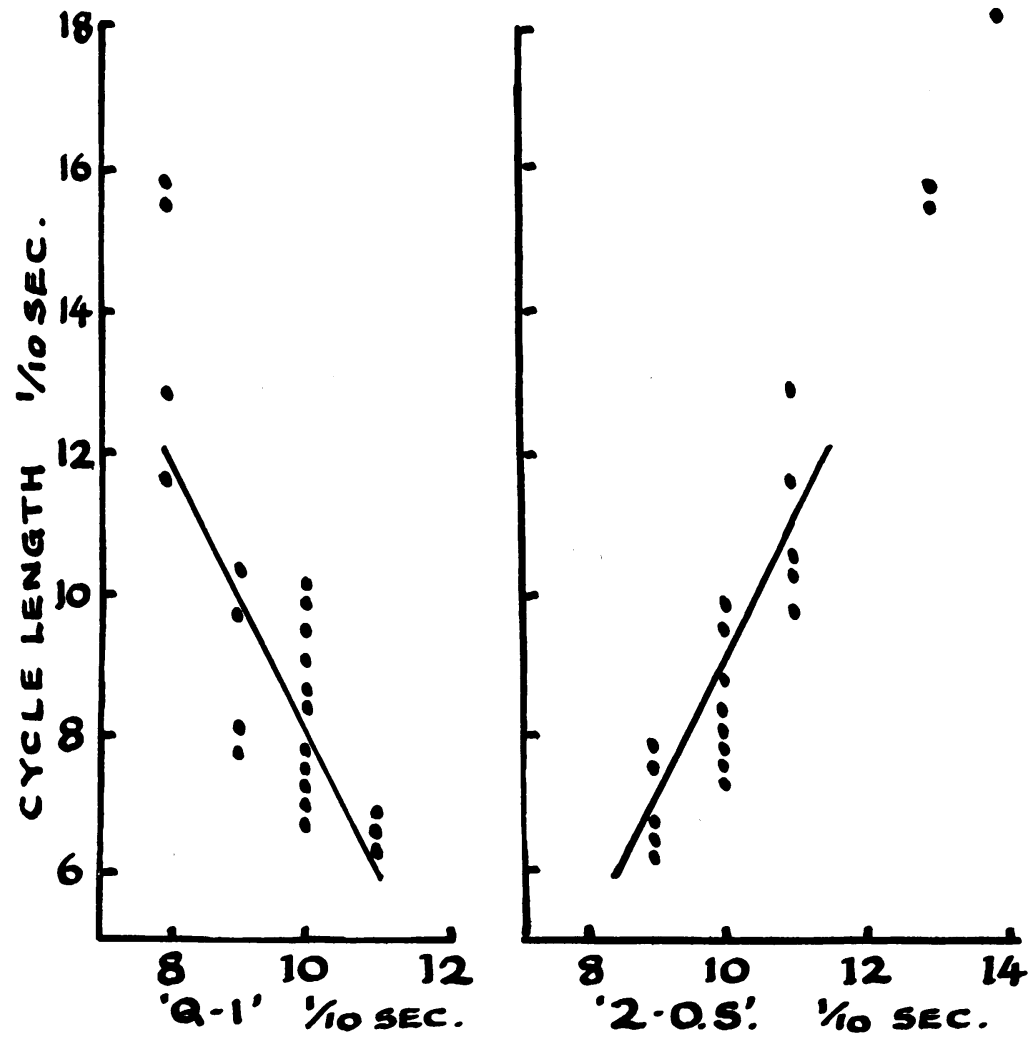

FIG. 2.-Graphs from a patient with auricular fibrillation illustrating the relationship between the $\mathbf{Q}-1$ and 2-O.S. intervals and the R-R interval of the preceding cycle. The " corrected $Q-1$ " interval for a cycle length of $0.8 \mathrm{sec}$. is $1.0 \mathrm{sec}$., and the "corrected 2-O.S." interval is $0.95 \mathrm{sec}$. 


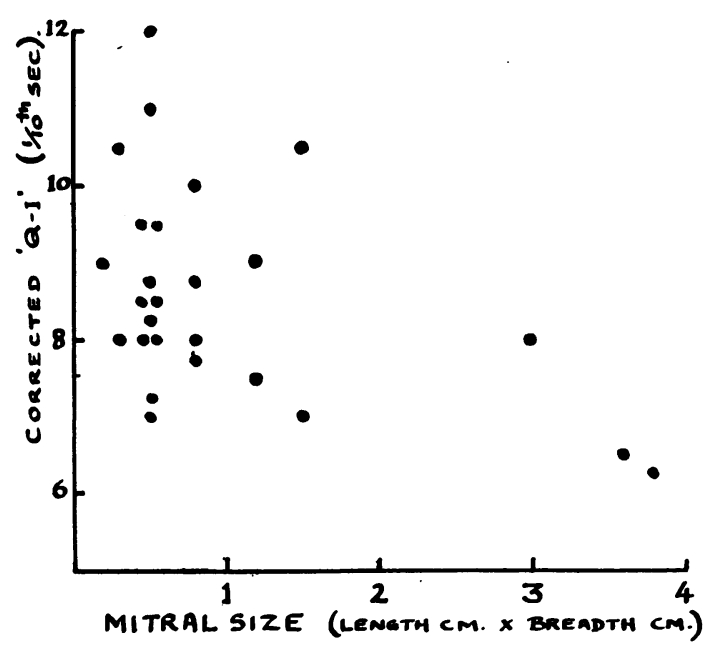

FIG. 3.-Scatter graphs of " corrected Q-1" and size of mitral orifice as found at operation.

The relationship between the size of the orifice and the Q-1 is shown in Fig. 3. This shows that when the Q-1 interval is short there is little stenosis of the mitral orifice, while a prolonged Q-1 interval may mean severe stenosis. It is probable, however, that there is some factor other than the size of the orifice that prolongs the Q-1 interval, and this will be discussed later.

The relationship between the size of the mitral orifice and the 2-O.S. interval is shown in Fig. 4, which shows that the shorter the interval the more severe is the mitral stenosis. The relationship is closer than in the case of the Q-1 interval and the shortest intervals are only seen in severe stenosis.

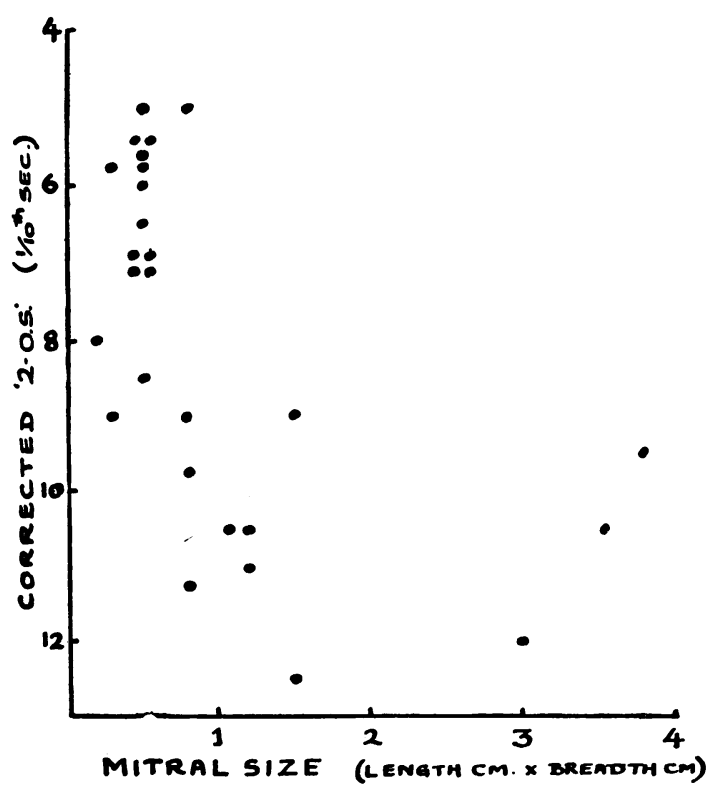

FIG. 4.-Scatter graph of " corrected 2-O.S." and size of mitral orifice as found at operation. 


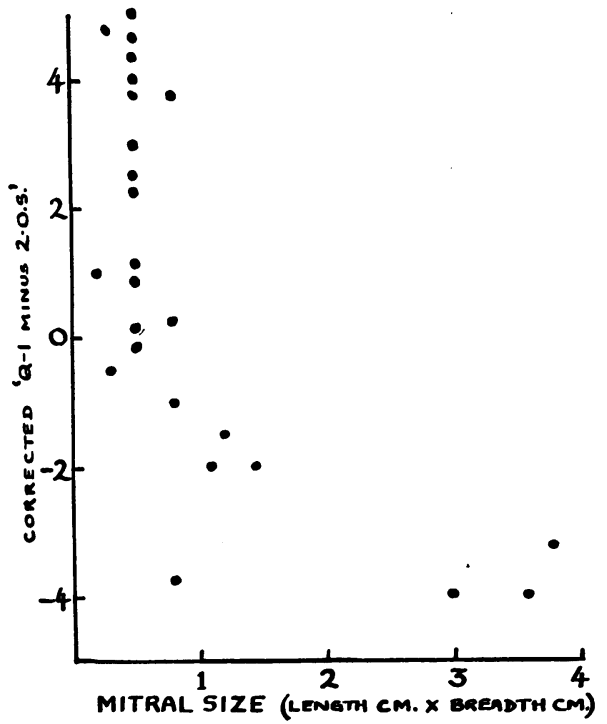

FIG. 5.-Scatter graph of " corrected Q-1" minus " corrected 2-O.S." and mitral size as found at operation

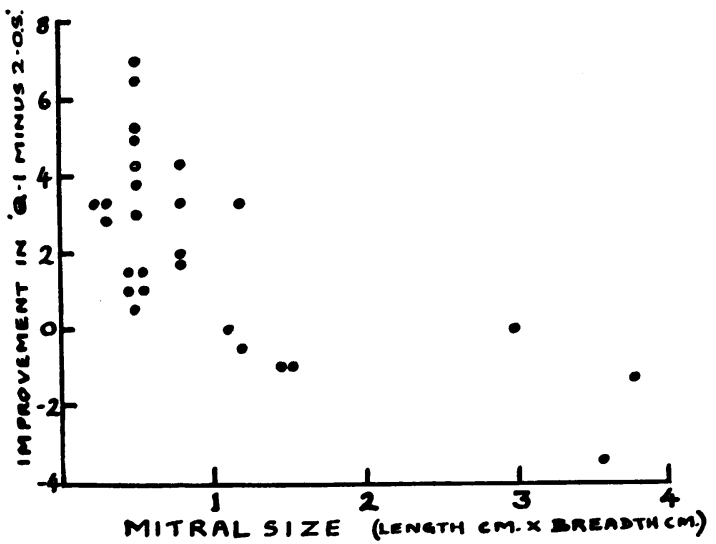

Fig. 6.-Scatter graph of improvement in Q-1 minus 2-O.S. following valvotomy and the size of the mitral orifice at operation.

The relationship between the size of the mitral orifice and the "corrected Q-1" minus the " corrected 2-O.S." is shown in Fig. 5: here the correlation is far closer. For figures between +5 and -1 the mitral orifice was always under $1 \times 1 \mathrm{~cm}$., while for figures between $-1 \frac{1}{2}$ and -4 , all but one of the mitral orifices were larger than $1 \times 1 \mathrm{~cm}$.

Finally the relationship between the degree of improvement of the phonocardiogram following valvotomy and the initial size of the mitral orifice is shown in Fig. 6. The improvement is estimated by contrasting Q-1 minus 2-O.S. before and after valvotomy. Here all but one of the patients showing improvement had orifices smaller than $1 \times 1 \mathrm{~cm}$. before operation. The only exception was a patient with an orifice $1.5 \times 0.8 \mathrm{~cm}$. All the patients showing no improvement had orifices larger than $1 \times 1 \mathrm{~cm}$.

\section{Discussion}

It is interesting that the Q-1 interval and the 2-O.S. interval when considered separately give less indication of the size of the mitral orifice than when they are combined. This may be because of the inaccuracy of measurement but other explanations come to mind. The theory that best fits the facts is that thickening of the mitral valve cusps alters the time of valve movement. Slight rigidity of the cusps might cause a delay in the first heart sound because the ventricular pressure would need to be considerably higher than the atrial pressure before the valve cusps would suddenly bulge into the atrium. During diastole the converse would apply, namely, that the atrial pressure would have to be higher than the ventricular pressure before the opening snap occurred. The combined figure of Q-1 minus 2-O.S. would be unaffected by rigidity of the valve cusps. Indeed the degree of difference from the predicted Q-1 and 2-O.S. might well be an indication of the rigidity of the cusps.

Having described the methods and findings in this investigation we must now consider whether the results are such as to be of practical value. The combined figures of Q-1 minus 2-O.S. will separate almost completely the patients with marked mitral stenosis from those whose orifice is over $1 \times 1 \mathrm{~cm}$. In addition the test shows some evidence that the patients with larger orifices are not benefited by surgical operation in the same way as those with smaller orifices (Fig. 6). This does not mean that an operation is not indicated for these patients, for the test we are considering is 
conducted while at rest in bed and has no direct bearing on the capacity of the patient to increase his cardiac output. The phonocardiogram is thus of value not only in determining with accuracy the presence or absence of an opening snap, but it may give an accurate indication of the severity of the mitral stenosis and the state of the valve cusps. This is only a preliminary communication and when other factors are studied the test may be shown to have even greater value. For instance the size of the mitral orifice is no indication of the severity of the mitral stenosis unless the size of the patient is considered. The onset of the QRS in lead II should be corrected if there is evidence of an isoelectric phase. All readings when the patient is excited or upset should be discarded or repeated under better conditions. When these and other features are considered the results may be of even greater value.

\section{SUMMARY}

A method is described of estimating the severity of mitral stenosis by means of a logarithmic phonocardiogram with synchronous electrocardiogram. The following measurements are made: (1) Q-1 interval (onset of QRS to onset of maximal vibrations of first heart sound), (2) 2-O.S. interval (onset of second sound to onset of opening snap), and (3) R-R interval (length of the preceding cardiac cycle).

The Q-1 and 2-O.S. intervals corresponding to a cycle length of $0.8 \mathrm{sec}$. are obtained from a graph of these measurements.

If the Q-1 minus 2-O.S. is over -1 , there is probably severe mitral stenosis and valvotomy will lower the pressure gradient across the mitral valve, even when the patient is at rest. If it is more negative than $-1 \cdot 5$, the mitral orifice is probably over $1 \times 1 \mathrm{~cm}$. and there is evidence that valvotomy will not improve the hæmodynamics at rest.

When the Q-1 and 2-O.S. intervals are considered separately they may give information as to the degree of rigidity of the mitral valve cusps.

The deductions in this study are based on the analysis of phonocardiograms before and after valvotomy in thirty patients.

I am indebted to Mr. O. S. Tubbs and Mr. I. M. Hill for permission to study their patients before and after operation. All but one of this series was operated upon by them in the Thoracic Surgical Unit, St. Bartholomew's Hospital. I am indebted to Mr. R. C. Brock for the operative findings in the remaining case.

\section{REFERENCES}

Messer, A. L., Counihan, T. B., Rappaport, M. B. and Sprague, H. B. (1951). Circulation, 4, 576. Wells, B. G. (1952). Brit. Heart J., 14, 261.

Rappaport, M. B., and Sprague, H. B. (1949). Amer. Heart J., 37, 586. 